\title{
Long-term impact of chronic total occlusion recanalisation in patients with ST-elevation myocardial infarction
}

\author{
Joëlle Elias, ${ }_{1}^{1}$ Ivo M van Dongen, ${ }^{1}$ Truls Råmunddal, ${ }^{2}$ Peep Laanmets, ${ }^{3}$ Erlend Eriksen, ${ }^{4}$ \\ Martijn Meuwissen, ${ }^{5} \mathrm{H}$ Rolf Michels, ${ }^{6}$ Matthijs Bax, ${ }^{7}$ Dan loanes, ${ }^{2}$ \\ Maarten Jan Suttorp, ${ }^{8}$ Bradley H Strauss, ${ }^{9}$ Emanuele Barbato, ${ }^{10}$ Koen M Marques, ${ }^{11}$ \\ Bimmer E P M Claessen, ${ }^{1}$ Alexander Hirsch, ${ }^{12}$ René J van der Schaaf, ${ }^{13}$ Jan G P Tijssen, ${ }^{1}$ \\ José P S Henriques, ${ }^{1}$ Loes P Hoebers, ${ }^{1}$ on behalf of the EXPLORE investigators
}

\begin{abstract}
- Additional material is published online only. To view, please visit the journal online (http://dx.doi.org/10.1136/ heartjnl-2017-312698).

For numbered affiliations see end of article.
\end{abstract}

\section{Correspondence to} of Cardiology, Academic Medical Center, University of Amsterdam, Amsterdam 1105 AZ, The Netherlands; j.elias@ amc.uva.nl

Received 8 November 2017 Revised 4 January 2018 Accepted 13 January 2018 Published Online First 20 February 2018
Miss Joëlle Elias, Department

\section{ABSTRACT}

Background During primary percutaneous coronary intervention (PCI), a concurrent chronic total occlusion (CTO) is found in $10 \%$ of patients with ST-elevation myocardial infarction (STEMI). Long-term benefits of CTO-PCI have been suggested; however, randomised data are lacking. Our aim was to determine mid-term and long-term clinical outcome of CTO-PCI versus CTONo $\mathrm{PCl}$ in patients with STEMI with a concurrent CTO. Methods The Evaluating Xience and left ventricular function in $\mathrm{PCI}$ on occlusiOns afteR STEMI (EXPLORE) was a multicentre randomised trial that included 302 patients with STEMI after successful primary PCI with a concurrent CTO. Patients were randomised to either CTO$\mathrm{PCl}$ or CTO-No PCI. The primary end point of the current study was occurrence of major adverse cardiac events (MACE): cardiac death, coronary artery bypass grafting and MI. Other end points were 1-year left ventricular function (LVF); LV-ejection fraction and LV end-diastolic volume and angina status.

Results The median long-term follow-up was 3.9 (2.1-5.0) years. MACE was not significantly different between both arms $(13.5 \%$ vs $12.3 \%, \mathrm{HR} 1.03,95 \% \mathrm{Cl}$ 0.54 to $1.98 ; P=0.93)$. Cardiac death was more frequent in the CTO-PCI arm $(6.0 \%$ vs $1.0 \%, P=0.02)$ with no difference in all-cause mortality $(12.9 \%$ vs $6.2 \%$, HR 2.07, $95 \% \mathrm{Cl} 0.84$ to 5.14; $\mathrm{P}=0.11)$. One-year LVF did not differ between both arms. However, there were more patients with freedom of angina in the CTO-PCI arm at 1 year ( $94 \%$ vs $87 \%, P=0.03)$.

Conclusions In this randomised trial involving patients with STEMI with a concurrent CTO, CTO-PCI was not associated with a reduction in long-term MACE compared to CTO-No PCI. One-year LVF was comparable between both treatment arms. The finding that there were more patients with freedom of angina after CTO$\mathrm{PCl}$ at 1-year follow-up needs further investigation.

Clinical trial registration EXPLORE trial number NTR1108 www.trialregister.nl.

- http://dx.doi.org/10.1136/ heartjnl-2018-312940

\section{Check for updates}

To cite: Elias J,

van Dongen IM,

Råmunddal T, et al. Heart

2018;104:1432-1438.

\section{INTRODUCTION}

During primary percutaneous coronary intervention (PCI), a concurrent chronic total occlusion (CTO) in a non-infarct-related artery is (accidentally) found in about $10 \%-15 \%$ of patients with ST-segment elevation myocardial infarction (STEMI). ${ }^{12}$ The presence of this concurrent CTO is a strong predictor for both short-term and longterm mortality. ${ }^{134}$ The adverse impact of a CTO in patients with STEMI is present in an early phase after primary PCI and remains consistently even after excluding the early deaths. ${ }^{5}$ In elective setting, long-term benefits of CTO-PCI have been suggested: improved survival, reduced need for coronary artery bypass grafting (CABG) and a lower incidence of future myocardial infarction (MI). ${ }^{67} \mathrm{In}$ successfully treated patients with STEMI, the Evaluating Xience and left ventricular function in PCI on occlusiOns afteR STEMI (EXPLORE) was the first randomised trial that evaluated the effect of routine early CTO-PCI (within 7 days postprimary PCI) versus a conservative strategy (cq. CTO-No PCI). The primary end point was not met: CTO-PCI compared with CTO-No PCI did not result in higher left ventricular ejection fraction (LVEF) and lower left ventricular end-diastolic volume (LVEDV). However, follow-up was relatively short (4 months) without any differences in the low major adverse cardiac event (MACE) rates in both arms $(5.4 \%$ vs $4.0 \%, \mathrm{P}=0.25)$ and angina status was not reported. ${ }^{8}$ For this reason, our objective was to evaluate the effect of CTO-PCI compared with CTO-No PCI on mid-term and long-term clinical outcome, LV function (LVF) and angina status in patients with STEMI with a concurrent CTO.

\section{METHODS}

\section{Study patients}

Study trial design, methods and results were described previously. ${ }^{89}$ Briefly, the EXPLORE trial consisted of 302 patients, who after successful primary PCI gave written informed consent, of which 148 patients were randomised to CTO-PCI within 7 days post-STEMI and 154 patients to CTO-No PCI for at least 4 months. The two randomisation arms were comparable with respect to baseline characteristics (see online supplementary table 1). In the CTO-PCI arm, the CTO-PCI was performed on average at $5.0 \pm 1.9$ days post-STEMI and one patient refused CTO-PCI. In the CTO-PCI arm, the investigator-reported procedural success 
rate was $77 \%$, the core lab adjudicated success rate was $73 \%$. Patients with successful CTO-PCI received on average two stents (1-3) for the CTO lesion of which $90 \%$ received everolimus-eluting stents. There were no significant differences between the two treatment arms regarding the primary end points; LVEF and LVEDV at 4 months. The study was conducted in accordance with the Declaration of Helsinki.

\section{Angiographic and cardiovascular magnetic resonance core lab analyses}

All baseline coronary angiograms, (non)-CTO-PCI procedural characteristics and complications were adjudicated by an independent dedicated blinded core lab and calculation of synergy between percutaneous coronary intervention with TAXUS and cardiac surgery (SYNTAX) scores was performed by Cardialysis, Rotterdam. An independent core lab (Clinfact Core Lab, Leiden, the Netherlands) performed quality control and blinded central analysis of the cardiovascular magnetic resonance (CMR) images using dedicated software (QMass MR analytical software V.7.6 Medis BV, Leiden, the Netherlands). CMR methods were previously described. ${ }^{8}$

\section{Outcomes}

To assess clinical status and adverse events, patients were seen at the outpatient clinic 4 months and 1 year after randomisation. At 2, 3, 4 and 5 years, clinical follow-up was performed through telephone contact. Patients were asked for their angina status (Canadian Cardiovascular Society grading of angina pectoris (CCS)) and dyspnoea class (New York Heart Association functional classification (NYHA)). All potential outcome events were recorded in a dedicated database. If a patient could not be contacted, information was obtained from the treating cardiologist, hospital records or general practitioner. Data were censored at 5 years (1826 days) of follow-up or known date of last contact. All clinical events were adjudicated by a clinical event committee blinded for randomisation outcome. The primary end point for this study was MACE, defined as the composite of cardiac death, MI and CABG. Other clinical end points included all-cause death, (repeat) PCI, stent thrombosis, stroke and major bleeding. The definition of cardiac death was according to the Academic Research Consortium (ARC) criteria and the definition of MI according to the third universal definition of MI criteria. All MI consisted of spontaneous (type 1), periprocedural (type 4a) and related to stent thrombosis (type 4b). Target-lesion PCI was characterised as PCI of the (treated) CTO lesion according to ARC criteria. Any repeat PCI was defined as a repeat PCI excluding the planned staged PCIs within the first 7 days. In our original protocol, the decision to perform PCI of non-target lesion revascularisation (non-TLR) co-existing lesions had to be made before randomisation and this additional PCI procedure must have been performed within 1 week after the index STEMI. After the first week, revascularisation was only indicated when clinically and/or ischaemia driven and preferably performed after 4 months. ${ }^{9}$ The definition of stent thrombosis was according to ARC criteria. ${ }^{10}$ At 1 -year follow-up, patients were asked to undergo an additional CMR.

\section{Statistical analysis}

Analyses were performed on intention-to-treat analysis. The as-treated analysis was performed in all patients with an attempted CTO-PCI before 6 months follow-up compared with CTO-No PCI within 6 months. Categorical data were expressed as frequencies (percentages) and continuous data as mean $( \pm \mathrm{SD})$. The statistical comparisons of the treatment arms were performed using the independent-samples t-test, or Fisher's exact probability test in case of binary end points. For the cumulative event rates of MACE and other end points, Kaplan-Meier curves displaying the pattern of events over the follow-up period were constructed and compared using the log-rank test. Hazard ratios (HR) with 95\% CIs were obtained with Cox proportional hazards models with treatment allocation as the only covariate. The proportional hazards assumptions were verified by graphical examination and by testing the statistical significance of the interaction between treatment and time. For hypothesis generating purposes only a post hoc subgroup analysis was performed in the a priori selected subgroups from the main trial, using formal testing for interaction. Ten baseline characteristics were examined for both outcomes: MACE and mortality. On the basis of change alone up to two statistically significant interaction tests would be expected $(\mathrm{P}<0.05)$. All $\mathrm{P}$ values were two-sided and a $P$ value of $<0.05$ was considered to be statistically significant. Statistical analysis was performed with the Statistical Package for Social Sciences software (SPSS V.23.0 for windows).

\section{RESULTS}

A total of 302 patients with STEMI with a concurrent CTO were included and randomised to CTO-PCI within 7 days $(n=148)$ or CTO-No PCI within 4 months $(n=154)$ (see online supplementary table 1 ). The median follow-up of the total group was 3.9 (2.1-5.0) years for clinical outcome. During long-term follow-up, 21 patients died, 14 in the CTO-PCI and 7 in the CTO-No PCI arm.

\section{One-year follow-up}

All patients completed 1-year follow-up. There was no significant difference in MACE between the CTO-PCI and the CTO-No PCI arm $(7.4 \%$ vs $6.5 \%, \mathrm{P}=0.82)$ after 1 -year follow-up (table 1$)$. A total of 94 patients underwent CMR at 1-year follow-up. At 1 year, mean LVEF was $45.5 \% \pm 9.1 \%$ in the CTO-PCI arm and $44.6 \% \pm 10.7 \%$ in the CTO-No PCI arm $(\mathrm{P}=0.66)$. Mean LVEDV was $198.0 \pm 44.8 \mathrm{~mL}$ in the CTO-PCI arm vs $208.1 \pm 50.9 \mathrm{~mL}$ in the CTO-No PCI arm $(\mathrm{P}=0.31)$ (table 2$)$. In patients with paired CMR data (baseline and 1-year follow-up), there was also no difference in recovery of global functional outcomes between CTO-PCI and CTO-No PCI (see online supplementary table 2).

\section{Long-term clinical outcome}

The Kaplan-Meier estimates for the composite end point of MACE were not significantly different between the treatment arms (13.5\% vs $12.3 \%$, HR $1.03,95 \%$ CI 0.54 to $1.98 ; \mathrm{P}=0.93)$ (figure 1). However, cardiac death occurred significantly more in the CTO-PCI arm compared with CTO-No PCI (6.0\% vs $1.0 \%$, $\mathrm{P}=0.02)$ with no significant difference in all-cause mortality (12.9\% vs $6.2 \%$, HR 2.07 , 95\% CI 0.84 to $5.14 ; \mathrm{P}=0.11$ ) (figure 2). The causes of all the deaths in relation to baseline characteristics and randomisation outcome are shown in table 3. Three patients in the CTO-PCI arm underwent CABG versus five in the CTO-No PCI arm $(2.1 \%$ vs $3.5 \%)$, for MI this was 12 vs 13 patients $(9.2 \%$ vs $8.7 \%)$ (table 1$)$.

The occurrence of any repeat PCI was not significantly different between the treatment strategies $(25.7 \%$ vs $29.3 \%$, HR $0.74,95 \%$ CI 0.46 to $1.16 ; \mathrm{P}=0.19$ ) (see online supplementary figure 1). More than $20 \%$ of the patients $(n=36)$ in the CTO-No PCI arm did eventually undergo CTO-PCI (between 1 and 1257 days after randomisation) and in the CTO-PCI arm 13 patients (9.9\%) underwent repeat PCI of the CTO lesion 


\begin{tabular}{|c|c|c|c|c|}
\hline & $\begin{array}{l}\text { CTO-PCI } \\
(n=148) \\
\end{array}$ & \multicolumn{2}{|c|}{$\begin{array}{l}\text { CTO-No PCl } \\
(n=154)\end{array}$} & $P$ value \\
\hline \multicolumn{5}{|c|}{ MACE at 4-month follow-up } \\
\hline $\begin{array}{l}\text { Composite of } \\
\text { cardiac death/MI/ } \\
\text { CABG surgery surgery }\end{array}$ & $8(5 \cdot 4 \%)$ & \multicolumn{2}{|l|}{$4(2 \cdot 6 \%)$} & $0 \cdot 25$ \\
\hline Cardiac death & $4(2 \cdot 7 \%)$ & \multicolumn{2}{|l|}{$\begin{array}{l}0 \\
-\end{array}$} & 0.06 \\
\hline $\mathrm{Ml}$ & $5(3 \cdot 4 \%)$ & \multicolumn{2}{|l|}{$3(1.9 \%)$} & 0.49 \\
\hline Periprocedural & 4 & \multicolumn{2}{|l|}{1} & - \\
\hline CABG surgery & - & \multicolumn{2}{|l|}{$1(0 \cdot 6 \%)$} & - \\
\hline \multicolumn{5}{|c|}{ MACE at 1-year follow-up } \\
\hline $\begin{array}{l}\text { Composite of } \\
\text { cardiac death/MI/ } \\
\text { CABG surgery surgery }\end{array}$ & $11(7 \cdot 4 \%)$ & \multicolumn{2}{|l|}{$10(6 \cdot 5 \%)$} & 0.82 \\
\hline Cardiac death & $4(2 \cdot 7 \%)$ & \multicolumn{2}{|l|}{$\begin{array}{l}0 \\
-\end{array}$} & 0.06 \\
\hline $\mathrm{Ml}$ & $8(5 \cdot 8 \%)$ & \multicolumn{2}{|l|}{$9(5 \cdot 8 \%)$} & 0.79 \\
\hline Periprocedural & 4 & \multicolumn{2}{|l|}{2} & - \\
\hline \multirow[t]{2}{*}{ CABG surgery } & $3(2 \cdot 0 \%)$ & \multicolumn{2}{|l|}{$1(0 \cdot 6 \%)$} & $0 \cdot 36$ \\
\hline & $\begin{array}{l}\text { CTO-PCl } \\
(n=148)\end{array}$ & $\begin{array}{l}\text { CTO-No PCI } \\
(n=154)\end{array}$ & HR $(95 \% \mathrm{Cl})$ & $\begin{array}{l}\text { Log-rank } \\
\text { P value }\end{array}$ \\
\hline \multicolumn{5}{|c|}{ MACE long-term (median 3.9 years) } \\
\hline $\begin{array}{l}\text { Composite of cardiac } \\
\text { death/MI/CABG }\end{array}$ & $18(13 \cdot 5 \%)$ & $18(12 \cdot 3 \%)$ & $1.03(0.54-1.98)$ & 0.93 \\
\hline Cardiac death & $8(6 \cdot 0 \%)$ & $1(1.0 \%)$ & & 0.02 \\
\hline $\mathrm{Ml}$ & $12(9 \cdot 2 \%)$ & $13(8 \cdot 7 \%)$ & & 0.74 \\
\hline Periprocedural & 4 & 2 & & - \\
\hline CABG operation & $3(2 \cdot 1 \%)$ & $5(3 \cdot 5 \%)$ & & 0.53 \\
\hline
\end{tabular}

during follow-up. The number of events for stent thrombosis, stroke and bleeding are given in table 4 .

For the end point of long-term MACE, there was a significant interaction between two-vessel disease and randomised treatment assignment $(\mathrm{P}=0.01)$. In patients with two-vessel disease, MACE rates were lower in the CTO-PCI arm compared with CTO-No PCI. Other subgroup analyses revealed no further significant interactions between CTO-PCI and CTO-No PCI with respect to age, gender, diabetes, culprit location, CTO location, baseline

Table 2 Imaging outcomes at 1-year follow-up

\begin{tabular}{|c|c|c|c|}
\hline Intention to treat & CTO-PCI $(n=45)$ & CTO-No PCI $(n=49)$ & $P$ value \\
\hline $\begin{array}{l}\text { Left ventricular ejection } \\
\text { fraction }(\%)\end{array}$ & $45.5(9.1)$ & $44.6(10.7)$ & 0.66 \\
\hline $\begin{array}{l}\text { Left ventricular end-diastolic } \\
\text { volume }(\mathrm{mL})\end{array}$ & $198.0(44.8)$ & $208.1(50.9)$ & 0.31 \\
\hline $\begin{array}{l}\text { Left ventricular end-systolic } \\
\text { volume }(\mathrm{mL})\end{array}$ & $108.9(34.8)$ & $118.2(46.3)$ & 0.27 \\
\hline As treated* & CTO-PCI $(n=53)$ & CTO-No PCI $(n=41)$ & \\
\hline $\begin{array}{l}\text { Left ventricular ejection } \\
\text { fraction }(\%)\end{array}$ & $45.4(9.0)$ & $44.4(11.0)$ & 0.62 \\
\hline $\begin{array}{l}\text { Left ventricular end-diastolic } \\
\text { volume }(\mathrm{mL})\end{array}$ & 197.5 (45.4) & 210.7 (50.9) & 0.19 \\
\hline $\begin{array}{l}\text { Left ventricular end-systolic } \\
\text { volume }(\mathrm{mL})\end{array}$ & $109.1(36.3)$ & $119.8(46.6)$ & 0.22 \\
\hline \multicolumn{4}{|c|}{$\begin{array}{l}\text { CMR data are mean } \pm \text { SD. } \\
{ }^{*} \text { As-treated analysis of the patients with an attempted CTO-PCI before 6-month } \\
\text { follow-up. }\end{array}$} \\
\hline
\end{tabular}

\section{Long-term MACE}

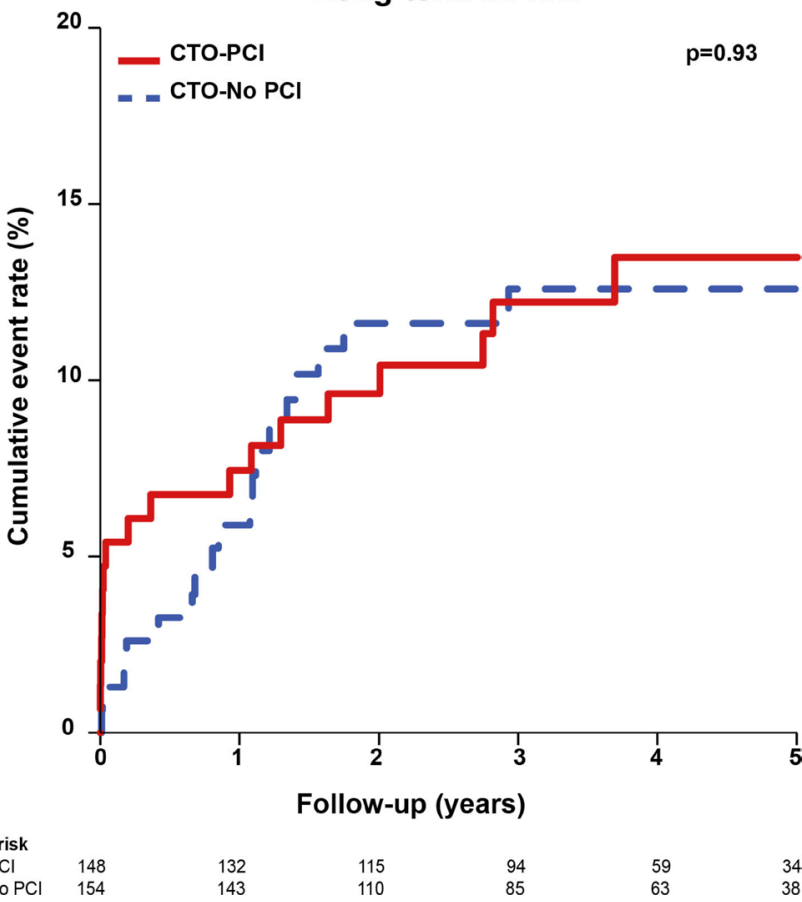

Figure 1 Clinical effect of early CTO-PCI vs CTO-No PCI on MACE in patients with ST-elevation myocardial infarction with a concurrent CTO: long-term follow-up. Kaplan-Meier estimates of the cumulative event rate of the composite end point of MACE: cardiac death, CABG and MI. Analyses were performed on a intention-to-treat basis. CTO, chronic total occlusion; $C A B G$, coronary artery bypass graft; $M A C E$, major adverse cardiac events; $\mathrm{Ml}$, myocardial infarction; $\mathrm{PCl}$, percutaneous coronary intervention.

LVEF, baseline LVEDV and SYNTAX score nor for the end point long-term mortality (see online supplementary figures 2 and 3).

\section{Prognostic factors for clinical outcome}

For explorative purposes, we analysed the study population combined; higher long-term MACE rates were seen in patients who had a SYNTAX score greater than the mean $(17 \%$ vs $8 \%$; HR 2.31; 95\% CI 1.16 to $4.63 ; \mathrm{P}=0.02)$. Long-term mortality was higher in patients who were older ( $>60$ years) $(11 \%$ vs $3 \%$; HR 3.74; 95\% CI 1.37 to $10.21 ; \mathrm{P}=0.01)$, who had diabetes (15\% vs 6\%; HR 2.94; 95\% CI 1.19 to $7.30 ; \mathrm{P}=0.02$ ), a higher LVEDV at baseline (12\% vs 1\%; HR 13.04; 95\% CI 1.70 to $100.30 ; \mathrm{P}=0.01)$ and who had a high SYNTAX score $(10 \%$ vs $4 \%$; HR $2.50 ; 95 \%$ CI 1.01 to $6.20 ; \mathrm{P}=0.048$ ) (see online supplementary tables 3 and 4 ).

\section{Successful versus failed CTO-PCI}

In the patients who underwent CTO-PCI $(n=147)$, long-term outcomes for successful $(n=106)$ versus failed CTO-PCI $(n=41)$ were compared. Long-term MACE was not significantly different between the successful and failed CTO-PCI arms $(\mathrm{P}=0.66)$. Also all-cause mortality was not significantly different between the two arms (see online supplementary figures 4 and 5).

\section{Angina and dyspnoea status at follow-up}

In online supplementary table 5, NYHA dyspnoea class, CCS angina status and medication at 1-year follow-up are described. At 1-year follow-up, the angina status was recorded from 291 (96\%) patients. There were more patients with freedom of 


\section{Long-term mortality}

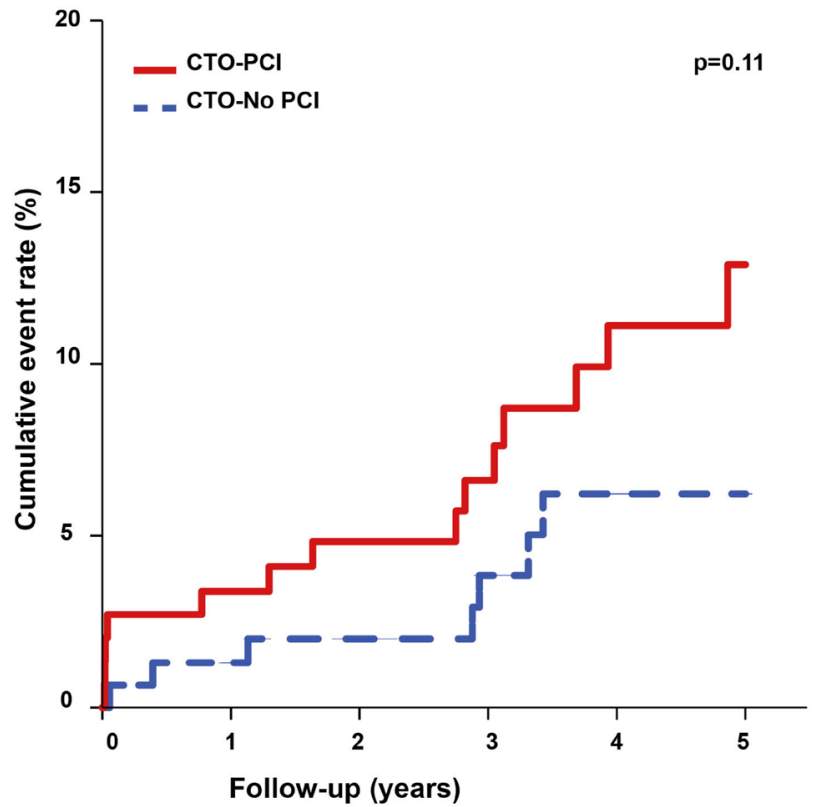

No. at risk CTO-PCl CTO-No PCI

139

123
126

100
99

66
71

38
43

Figure 2 Long-term mortality comparing CTO-PCI vs CTO-No PCl in patients with ST-elevation myocardial infarction with a concurrent CTO. Kaplan-Meier estimates of the cumulative event rates of mortality. Analyses were performed on a intention-to-treat basis. CTO, chronic total occlusion; $\mathrm{PCl}$, percutaneous coronary intervention.

angina in the CTO-PCI arm compared with CTO-No PCI $(94 \%$ vs $87 \%, \mathrm{P}=0.03)$. After 1 -year follow-up, there were no significant differences in angina complaints between the CTO-PCI and CTO-No PCI arms (figure 3 ).

\section{DISCUSSION}

The EXPLORE trial is the first randomised trial presenting longterm data on the effect of additional CTO-PCI versus CTO-No PCI after successful primary PCI in patients with STEMI with a concurrent CTO. This present study confirms and extends the previous short-term results from the EXPLORE trial. ${ }^{8}$ We could not demonstrate a beneficial effect of routine early CTO-PCI on MACE at long-term follow-up nor on 1-year LVF. However, we did find a significantly higher rate of cardiac death in patients randomised to CTO-PCI at a median of 3.9 years follow-up. Furthermore, we found that patients randomised to CTO-PCI had less angina complaints at 1 year follow-up. Although this trial was not powered for clinical end points, it is thus far the only trial to randomly compare CTO-PCI versus CTO-No PCI in patients with STEMI, and it is the only trial reporting longterm follow-up.

To date, earlier observational studies reported that in elective as well as in patients with STEMI successful compared with failed CTO-PCI was associated with improved clinical outcome at follow-up. ${ }^{11-15}$ However, Lee et al found no association of successful CTO-PCI on survival in 1173 elective patients with CTO. ${ }^{16}$ Nonetheless, previous studies were not randomised and lacked a comparison with a conservative control (CTO-No PCI). The Drug-Eluting Stent Implantation Versus Optimal Medical Treatment in Patients with Chronic Total Occlusion

(DECISION-CTO) trial was the first randomised study in elective patients with CTO with stable angina. ${ }^{17}$ The primary end point of all-cause mortality, MI, stroke and revascularisation did not differ between CTO-PCI or optimal medical therapy only (OMT) $(n=834)$. In the EuroCTO trial at 1 -year follow-up any adverse event rates were not significantly different between CTO-PCI $(n=259)$ and OMT $(n=137) .{ }^{18}$ In the post-STEMI setting, the first and only randomised EXPLORE trial did also not show a significant difference in MACE between CTO-PCI and CTO-No PCI. Previous randomised trials in patients with

\begin{tabular}{|c|c|c|c|c|c|c|c|c|}
\hline $\begin{array}{l}\text { Patient } \\
\text { no }\end{array}$ & $\begin{array}{l}\text { Culprit } \\
\text { location }\end{array}$ & $\begin{array}{l}\text { СТО } \\
\text { location }\end{array}$ & $\begin{array}{l}\text { LVEF at } \\
\text { baseline (\%) }\end{array}$ & $\begin{array}{l}\text { Treatment } \\
\text { strategy }\end{array}$ & $\begin{array}{l}\text { Time to } \\
\text { CTO-PCI (days) }\end{array}$ & $\begin{array}{l}\text { CTO-PCI } \\
\text { successful }\end{array}$ & $\begin{array}{l}\text { Time to } \\
\text { death (days) }\end{array}$ & Cause of death \\
\hline 1 & LAD & LcX & 27 & I & 6 & Yes & 6 & Definite ST non-CTO lesion (autopsy) \\
\hline 2 & RCA & LAD & 38 & I & 4 & Yes & 7 & Found dead/probableST \\
\hline 3 & LAD & LcX & 45 & 1 & 7 & Yes & 8 & Found dead/probableST \\
\hline 4 & LcX & RCA & - & I & 7 & Yes & 14 & Heart failure after definite ST in CTO and culprit \\
\hline 5 & LAD & RCA & 17 & C & - & - & 20 & Stroke \\
\hline 6 & RCA & LAD & - & C & - & - & 143 & Stroke \\
\hline 7 & LCX & LAD & 54 & 1 & 3 & Yes & 282 & Stroke \\
\hline 8 & $\mathrm{LcX}$ & LAD & 9 & C & - & - & 413 & Pneumonia \\
\hline 9 & LAD & RCA & 17 & 1 & 4 & No & 473 & Heart failure \\
\hline 10 & LcX & RCA & 28 & I & 6 & Yes & 597 & Heart failure \\
\hline 11 & RCA & LAD & 25 & 1 & 3 & Yes & 1003 & Heart failure \\
\hline 12 & LAD & RCA & - & I & 5 & Yes & 1029 & Unexplained death \\
\hline 13 & RCA & LAD & 47 & C & - & - & 1050 & Malignancy \\
\hline 14 & LAD & RCA & - & C & - & - & 1070 & Unexplained death \\
\hline 15 & RCA & LAD & 16 & I & 7 & No & 1112 & Malignancy \\
\hline 16 & RCA & LAD & - & 1 & 6 & Yes & 1139 & Malignancy \\
\hline 17 & LAD & RCA & - & C & - & - & 1209 & Malignancy \\
\hline 18 & LAD & RCA & 37 & C & - & - & 1251 & Stroke \\
\hline 19 & RCA & LAD & - & I & 5 & Yes & 1345 & Lung embolic \\
\hline 20 & LAD & RCA & 46 & 1 & 2 & Yes & 1435 & Amyloidosis \\
\hline 21 & LAD & RCA & - & 1 & 3 & Yes & 1775 & Euthanasia \\
\hline
\end{tabular}

C, conservative strategy (CTO-No PCI); CTO, chronic total occlusion; I, invasive strategy (CTO-PCI); LAD, left anterior descending artery; LCX, left circumflex artery; LVEF, left ventricular function; $\mathrm{PCl}$, percutaneous coronary intervention; RCA, right coronary artery; ST, stent thrombosis. 
Table 4 Other clinical outcomes from randomisation until last known date of follow-up

\begin{tabular}{|c|c|c|c|c|}
\hline & СТO-PCI $(n=148)$ & CTO-No PCI (n=154) & HR $(95 \% \mathrm{Cl})$ & Log-rank $P$ value \\
\hline All-cause death & $14(12 \cdot 9 \%)$ & $7(6 \cdot 2 \%)$ & $2.07(0.84$ to 5.14$)$ & $0 \cdot 11$ \\
\hline Any repeat $\mathrm{PCl}$ & $32(25 \cdot 7 \%)$ & $42(29 \cdot 3 \%)$ & $0.74(0.46$ to 1.16$)$ & 0.19 \\
\hline Target lesion $\mathrm{PCI}^{*}$ & $13(9.9 \%)$ & $36(25.5 \%)$ & - & - \\
\hline Total stent thrombosis (definite/probable) & $6(4 \cdot 1 \%)$ & $6(4 \cdot 1 \%)$ & & 0.95 \\
\hline Stent thrombosis CTO lesion & 4 & 1 & & \\
\hline Definite & 2 & 1 & & \\
\hline Probable & 2 & 0 & & \\
\hline \multicolumn{5}{|l|}{ Timing of stent thrombosis } \\
\hline Acute & 0 & 0 & & \\
\hline Subacute & 3 & 0 & & \\
\hline Late & 0 & 0 & & \\
\hline Very late & 1 & 1 & & \\
\hline Stent thrombosis non-CTO lesion & 6 & 6 & & \\
\hline Definite & 4 & 6 & & \\
\hline Probable & 2 & 0 & & \\
\hline \multicolumn{5}{|l|}{ Timing of stent thrombosis } \\
\hline Acute & 0 & 1 & & \\
\hline Subacute & 5 & 2 & & \\
\hline Late & 0 & 0 & & \\
\hline Very late & 1 & 3 & & \\
\hline Stroke & $2(1 \cdot 5 \%)$ & $4(2 \cdot 9 \%)$ & & 0.28 \\
\hline Bleeding according to GUSTO criteria & $8(5 \cdot 5 \%)$ & $5(3 \cdot 3 \%)$ & & 0.34 \\
\hline Mild & 2 & 3 & & \\
\hline Moderate & 5 & 1 & & \\
\hline Severe or life threatening & 1 & 1 & & \\
\hline
\end{tabular}

Adjudicated clinical outcomes from randomisation to long-term follow-up. Data are numbers of patients with percentages. KM estimates from the Kaplan-Meier curves.

* The target lesion is defined as the CTO lesion.

СTO, chronic total occlusion; GUSTO, global use of strategies to open occluded coronary arteries; PCI, percutaneous coronary intervention, TLR, target lesion revascularisation.

STEMI with multivessel disease (mostly excluding CTO lesions) did show benefit of (staged) PCI after primary PCI compared with culprit-only PCI in terms of the composite end point. ${ }^{19-21}$ However, the benefit of staged multivessel PCI treatment was mainly due to a decrease in revascularisations with no significant decrease in mortality or recurrent MI. ${ }^{22}$

In the EXPLORE trial, we did find a higher number of cardiac deaths in patients randomised to CTO-PCI, which could be related to the post-STEMI setting and timing of CTO-PCI. The randomised CTO-PCI was performed after $5 \pm 2$ days (semi-acute phase) with the theoretical protective benefit of providing collateral supply during future events.

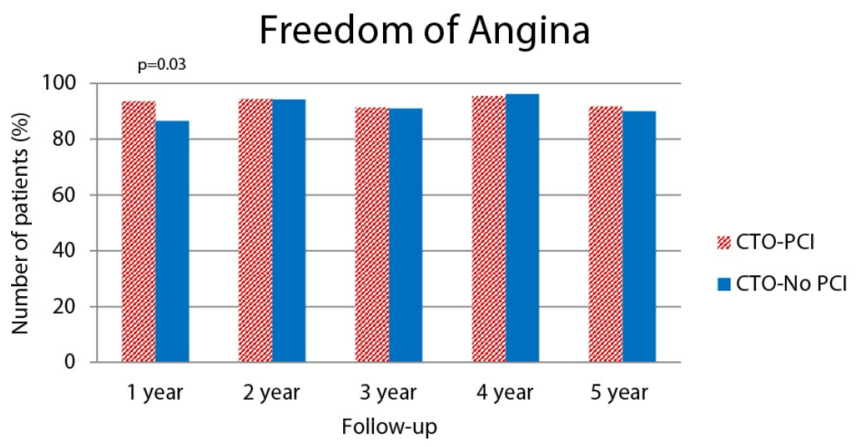

Figure 3 Angina status during follow-up comparing CTO-PCI vs CTO-No PCl in patients with ST-elevation myocardial infarction with a concurrent CTO. Percentage of patients with angina complaints during follow-up. CCS, Canadian Cardiovascular Society; CTO, chronic total occlusion; $\mathrm{PCl}$, percutaneous coronary intervention.
However, little is known about the potential harm of CTO-PCI early after primary PCI. During the acute setting of STEMI, and during the recovery, inflammation plays an important role, which could lead to larger infarct sizes and adverse LV remodelling after (staged) non-culprit PCI. ${ }^{23}{ }^{24}$ Nonetheless, the numbers are small and the difference in cardiac mortality does not seem to be directly related to the CTO-PCI procedure. Even though only $60 \%$ of the patients in the CTO-PCI arm was still on dual antiplatelet therapy at 1-year follow-up, no difference in the occurrence of stent thrombosis compared with patients with CTO-No PCI was found. Furthermore, only one deceased patient in the CTO-PCI arm had a stent thrombosis of the CTO together with a stent thrombosis of the culprit lesion. The remaining 7 patients died because of non-CTO stent thrombosis $(n=1)$, were found dead $(n=3)$ or heart failure $(n=3)$. Also it is noticeable that the incidence of cardiac death in the conservative arm is much lower than expected $(1 \%)$. Additionally, no serious procedure-related events and no periprocedural deaths occurred during CTO-PCI. Although not adequately powered, our trial showed the same risk factors for mortality as in previous studies: patients who are older, have diabetes, a lower LVEF or higher LVEDV at baseline, a higher SYNTAX score and a CTO located in the left anterior descending artery (LAD) have a worse outcome. ${ }^{2526}$

In the EXPLORE main paper, a significant interaction on LVEF was found in patients with a CTO in the LAD in favour of CTO-PCI. However, in-depth analysis of LV recovery in serial CMR data did not support this finding. ${ }^{27}$ Furthermore, subgroup analysis for long-term MACE and mortality revealed no significant interaction for CTO location. We did find a 
significant interaction between two-vessel disease and MACE which is difficult to explain. Unfortunately, we do not have data on the completeness of revascularisation and therefore it is possible that the patients with two-vessel disease in the CTO-PCI arm had a more complete (non-TLR) revascularisation status leading to improved outcome.

In the EXPLORE trial, we found that at 1-year follow-up there were numerically fewer patients with angina complaints in the CTO-PCI arm compared with CTO-No PCI. In the EuroCTO trial, CTO-PCI also improved the functional angina class compared with OMT at 12 months follow-up. Furthermore health status (angina frequency), physical limitations and quality of life were improved after CTO-PCI. ${ }^{18}$ In an observational prospective study of 50 patients with CTO with complete revascularisation, there were significant increases from baseline to 7-month follow-up in peak oxygen consumption $(+12.40 \%)$, work rate $(+13.63 \%)$, anaerobic threshold $(+27.87 \%)$ and oxygen pulse $(+8.75 \%)$. Furthermore, there was a significant improvement in NYHA and CCS classification. ${ }^{28}$ However, these effect were all seen at relatively shortterm follow-up (maximum of 1 year) and the effect of CTO-PCI on functional status beyond 1 year needs to be determined.

Our data emphasise the need for a careful selection of patients that will benefit from CTO-PCI by making a thorough risk/benefit assessment. According to the guidelines, treatment of CTO lesions should only be considered after objectives of viability or ischaemia in the CTO territory or expected relief in angina symptoms (class IIa, level B).$^{29}$ Nonetheless, thus far in randomised setting none of the conducted studies showed significant benefit of CTO-PCI compared with OMT on LVF nor on clinical outcome. Although in the EXPLORE CMR substudy, revascularisation of the dysfunctional myocardium supplied by the CTO resulted in a better recovery of regional LV function, when compared with CTO-No PCI $(\Delta$ SWT $17 \% \pm 27 \%$ vs $11 \pm 23 \%, \mathrm{P}=0.03){ }^{30}$ The Sham-Controlled Intervention to Improve Quality of Life in CTOs (SHINE-CTO: NCT02784418) will be the first sham-controlled trial to randomise patients to CTO-PCI or sham procedure to evaluate the effect of CTO-PCI on patients' symptoms. Although performing clinical CTO trials is challenging, randomised data on the real effects of CTO-PCI remain essential to establish if CTO-PCI is the optimal treatment or whether CTO-PCI can be postponed, as there are no clear beneficial effects and symptoms might decrease over time, in these more complex and high-risk patients.

\section{Study limitations}

There are several limitations applicable to this study. The EXPLORE trial was not powered to detect differences in clinical outcomes. As in most randomised controlled trials, a selection of patients has occurred. One-year CMR was optional in the study protocol and therefore only available in 94 patients. In the CTO-No PCI arm, there were 36 patients who did undergo CTO-PCI during follow-up, which makes evaluations of the real long-term effect of CTO-PCI more complex. Evaluation of the functional (angina) status was done during the follow-up (telephone) visits; however, no standardised angina assessments were used. The EXPLORE trial included over a period of 8 years and during this period there have been major improvements in procedural techniques and devices, together with increasing operator experiences. Nevertheless, the EXPLORE trial is thus far the only CTO trial that completed enrolment of the planned number of patients.

\section{CONCLUSION}

In patients with STEMI and a concurrent CTO, we found no difference in long-term MACE between the CTO-PCI arm and the CTO-No PCI arm. After the time-window for the primary end points $>20 \%$ of patients randomised to CTO-No PCI underwent elective CTO-PCI. There was a numerically higher cardiac death rate in the CTO-PCI arm with no difference in all-cause mortality. Nonetheless, there were more patients with freedom of angina at 1-year follow-up in the CTO-PCI compared with CTO-No PCI arm. Further research will be needed to explore if in selected patients CTO-PCI can reduce (angina) outcomes and improve cardiopulmonary exercise capacity.

\section{Key questions}

What is already known on this subject?

Observational studies have reported that in patients with ST-elevation myocardial infarction (STEMI) with a concurrent chronic total occlusion (CTO) successful compared with failed CTO-percutaneous coronary intervention (PCI) is associated with improved clinical outcome at follow-up. However, none of these studies was randomised and all studies lacked a comparison with a conservative control (CTO-No PCI).

\section{What might this study add?}

In this randomised trial involving patients with STEMI after successful primary $\mathrm{PCI}$ with a concurrent CTO, we could not demonstrate a beneficial effect of routine early CTO-PCI compared with CTO-NO PCl on major adverse cardiac events at long-term follow-up. However, we did find that patients randomised to CTO-PCl compared with CTO-No PCI had less frequent angina complaints at 1 year.

\section{How might this impact on clinical practice?}

Our findings do not support a routine early CTO-PCl in patients with STEMI presenting with a concurrent CTO during primary $\mathrm{PCl}$. Importantly, further randomised studies on the effects of CTO-PCl, compared with CTO-No PCl, are crucial to establish if СTO-PCl is the optimal treatment in these complex and high-risk patients.

\section{Author affiliations}

${ }^{1}$ Department of Cardiology, Academic Medical Center, University of Amsterdam, Amsterdam, The Netherlands

${ }^{2}$ Sahlgrenska University Hospital, Gothenburg, Sweden

${ }^{3}$ North-Estonia Medical Centre, Talinn, Estonia

${ }^{4}$ Haukeland University Hospital, Bergen, Norway

${ }^{5}$ Department of Cardiology, Amphia Hospital, Breda, The Netherlands

${ }^{6}$ Catharina Hospital, Eindhoven, The Netherlands

${ }^{7}$ Department of Cardiology, Haga Teaching Hospital, The Hague, The Netherlands

${ }^{8}$ Department of Cardiology, Sint Antonius Ziekenhuis, Nieuwegein, The Netherlands

${ }^{9}$ Sunnybrook Health Sciences Centre, Toronto, Canada

${ }^{10}$ Cardiovascular Center, Onze Lieve Vrouwe Ziekenhuis, Aalst, Belgium

${ }^{11}$ VU University Medical Center, Amsterdam, The Netherlands

${ }^{12}$ Erasmus Medical Center, Rotterdam, The Netherlands

${ }^{13}$ Department of Cardiology, Onze Lieve Vrouwe Gasthuis, Amsterdam, The Netherlands

Collaborators The following investigators and research coordinators participated in the EXPLORE trial (total number of patients recruited): Academisch Medisch Centrum, Amsterdam (78)—JPS Henriques, JJ Piek, RJ De Winter, KT Koch, MM Vis, J Baan, JJ Wykrzykowska, EM Scheunhage; Sahlgrenska University Hospital, Gothenburg, Sweden (61) — R Råmunddal, D loanes, EL Pommer; North Estonia Medical Center, Estonia (41)—P Laanmets, M Tamm; Onze Lieve Vrouwe Gasthuis. Amsterdam, The Netherlands (30)—RJ van der Schaaf, T Slagboom, G Amoroso, 
V Stolk; Haukeland University Hospital, Bergen, Norway (29)—E Eriksen, V Tuseth, LM Moldestad; Haga ziekenhuis, Den Haag, The Netherlands (17)—M Bax, CE Schotborgh, C de Jonge-Scheen; St. Antonius Ziekenhuis, Nieuwegein, The Netherlands (11)—MJ Suttorp, M Bosschaert, C Feirabend; Onze Lieve Vrouw Ziekenhuis, Aalst, Belgium (9)—E Barbato, H Batjoens; Sunnybrook Health Sciences Center, Toronto, Canada (9)—BH Strauss, P Reilly; VUMC, Amsterdam, The Netherlands (8) — KM Marques, EJ Verduyn; Quebec Heart-Lung Institute-Quebec, Canada (4)—O Bertrand; Amphia Ziekenhuis, Breda, The Netherlands (4) - $M$ Meuwissen, M Baas; Maasstad ziekenhuis, Rotterdam, The Netherlands (2) - M van der Ent, AF Haan; Catharina Ziekenhuis, Eindhoven, The Netherlands (1)—J Koolen, L van Leur. Trial Steering Committee-JPS Henriques (PI), RJ van der Schaaf (co-PI), JGP Tijssen. EXPLORE study coordinators-LP Hoebers, J Elias, IM van Dongen; Clinical Adjudication Committee-M Meuwissen, HR Michels; Monitoring — C Dille, Cordinamo, Weeze, The Netherlands; Clinical Cardiac Imaging Core Laboratory $-R$ Nijveldt, R Kooistra, JC Tuinenburg. Clinfact, Leiden, The Netherlands; Angiographic Adjudication Committee—P Agostoni, G van Houwelingen; Syntax score Adjudication Corelab_Cardialysis, Rotterdam, The Netherlands.

Contributors All authors attributed to the conception, design, critical revision and final approval of this manuscript. JE and LPH performed statistical analyses. JE interpreted the data and drafted the manuscript under supervision of senior authors JPSH, JGT and LPH.

Funding This investigator-initiated study was funded by the Academic Medical Center in combination with a research grant from Abbott Vascular.

Competing interests JPSH has received grants from Abbott Vascular during the conduct of the study; and has received grants from B. Braun, Abiomed and Biotronik outside the submitted work. RJvdS has received grants from Abbott Vascular, Biotronik and Biosensors; has received personal fees from Biotronik and Boston Scientific; has been a consultant for Biotronik and has received speakers fees from OrbusNeich, Boston Scientific and Asahi Intecc outside the submitted work. TR has been a proctor for Boston Scientific.

Patient consent Obtained.

Ethics approval The EXPLORE trial was approved by the central Medical Ethics Review Committee (METC) of the Academic Medical Center of Amsterdam (The Netherlands) and by all local ethics committees involved.

Provenance and peer review Not commissioned; externally peer reviewed.

(c) Article author(s) (or their employer(s) unless otherwise stated in the text of the article) 2018. All rights reserved. No commercial use is permitted unless otherwise expressly granted.

\section{REFERENCES}

1 Claessen BE, Dangas GD, Weisz G, et al. Prognostic impact of a chronic total occlusion in a non-infarct-related artery in patients with ST-segment elevation myocardial infarction: 3-year results from the HORIZONS-AMI trial. Eur Heart J 2012;33:768-75.

2 Råmunddal T, Hoebers LP, Hoebers L, et al. Chronic total occlusions in Sweden--a report from the Swedish Coronary Angiography and Angioplasty Registry (SCAAR). PLoS One 2014:9:e103850

3 Hoebers LP, Vis MM, Claessen BE, et al. The impact of multivessel disease with and without a co-existing chronic total occlusion on short- and long-term mortality in ST-elevation myocardial infarction patients with and without cardiogenic shock. Eur $\int$ Heart Fail 2013:15:425-32

4 Claessen BE, van der Schaaf RJ, Verouden NJ, et al. Evaluation of the effect of a concurrent chronic total occlusion on long-term mortality and left ventricular function in patients after primary percutaneous coronary intervention. JACC Cardiovasc Interv 2009:2:1128-34

5 Watanabe H, Morimoto T, Shiomi H, et al. Chronic total occlusion in a non-infarctrelated artery is closely associated with increased five-year mortality in patients with ST-segment elevation acute myocardial infarction undergoing primary percutaneous coronary intervention (from the CREDO-Kyoto AMI registry). EuroIntervention 2017:12:e1874-e1882.

6 Hoebers LP, Claessen BE, Elias J, et al. Meta-analysis on the impact of percutaneous coronary intervention of chronic total occlusions on left ventricular function and clinical outcome. Int J Cardiol 2015;187:90-6.

7 Christakopoulos GE, Christopoulos G, Carlino M, et al. Meta-analysis of clinical outcomes of patients who underwent percutaneous coronary interventions for chronic total occlusions. Am J Cardiol 2015:115:1367-75.

8 Henriques JP, Hoebers LP, Råmunddal T, et al. Percutaneous Intervention for Concurrent Chronic Total Occlusions in Patients With STEMI: The EXPLORE Trial. J Am Coll Cardiol 2016;68:1622-32.
9 van der Schaaf RJ, Claessen BE, Hoebers LP, et al. Rationale and design of EXPLORE: a randomized, prospective, multicenter trial investigating the impact of recanalization of a chronic total occlusion on left ventricular function in patients after primary percutaneous coronary intervention for acute ST-elevation myocardial infarction. Trials 2010;11:89.

10 Cutlip DE, Windecker S, Mehran R, et al. Clinical end points in coronary stent trials: a case for standardized definitions. Circulation 2007;115:2344-51.

11 Yang ZK, Zhang RY, Hu J, et al. Impact of successful staged revascularization of a chronic total occlusion in the non-infarct-related artery on long-term outcome in patients with acute ST-segment elevation myocardial infarction. Int I Cardiol 2013;165:76-9.

12 Shi G, He P, Liu Y, et al. Evaluation of the effect of concurrent chronic total occlusion and successful staged revascularization on long-term mortality in patients with STelevation myocardial infarction. ScientificWorldJournal 2014;2014:1-9.

13 Toma A, Gick M, Minners J, et al. Survival after percutaneous coronary intervention for chronic total occlusion. Clin Res Cardiol 2016;105:921-9.

14 Borgia F, Viceconte N, Ali O, et al. Improved cardiac survival, freedom from MACE and angina-related quality of life after successful percutaneous recanalization of coronary artery chronic total occlusions. Int J Cardiol 2012;161:31-8.

15 Tsai TT, Stanislawski MA, Shunk KA, et al. Contemporary incidence, management, and long-term outcomes of percutaneous coronary interventions for chronic coronary artery total occlusions: insights from the VA CART program. JACC Cardiovasc Interv 2017; 10:866-75.

16 Lee PH, Lee SW, Park HS, et al. Successful recanalization of native coronary chronic total occlusion is not associated with improved long-term survival. JACC CardiovasC Interv 2016;9:530-8.

17 Park SJ. D-CTO. Optimal medical therapy with or without stenting for coronary chronic total occlusion. Paper presented. Washington, DC: Annual meeting of the American College of Cardiology. March 182017.

18 Werner G. A randomized multicentre trial to evaluate the utilization of revascularization or optimal medical therapy for the treatment of chronic total coronary occlusions. Paper presented. Paris, France: Annual meeting of the European Association of percutaneous cardiovascular interventions. May 18, 2017.

19 Engstrøm T, Kelbæk H, Helqvist S, et al. Complete revascularisation versus treatment of the culprit lesion only in patients with ST-segment elevation myocardial infarction and multivessel disease (DANAMI-3_PRIMULTI): an open-label, randomised controlled trial. Lancet 2015;386:665-71.

20 Wald DS, Morris JK, Wald NJ, et al. Randomized trial of preventive angioplasty in myocardial infarction. N Engl J Med 2013;369:1115-23.

21 Gershlick AH, Khan JN, Kelly DJ, et al. Randomized trial of complete versus lesiononly revascularization in patients undergoing primary percutaneous coronary intervention for STEMI and multivessel disease: the CVLPRIT trial. J Am Coll Cardiol 2015;65:963-72.

22 Elgendy IY, Mahmoud AN, Kumbhani DJ, et al. Complete or culprit-only revascularization for patients with multivessel coronary artery disease undergoing percutaneous coronary intervention: a pairwise and network meta-analysis of randomized trials. JACC Cardiovasc Interv 2017;10:315-24.

23 Ohashi Y, Kawashima S, Mori T, et al. Soluble CD40 ligand and interleukin-6 in the coronary circulation after acute myocardial infarction. Int I Cardiol 2006;112:52-8.

24 Reindl M, Reinstadler SJ, Feistritzer HJ, et al. Relation of inflammatory markers with myocardial and microvascular injury in patients with reperfused ST-elevation myocardial infarction. Eur Heart J Acute Cardiovasc Care 2017;6.

25 Hoebers LP, Elias J, van Dongen IM, et al. The impact of the location of a chronic total occlusion in a non-infarct-related artery on long-term mortality in ST-elevation myocardial infarction patients. Eurolntervention 2016:12:423-30.

26 Råmunddal T, Hoebers LP, Henriques JP, et al. Prognostic impact of chronic total occlusions: a report from SCAAR (Swedish Coronary Angiography and Angioplasty Registry). JACC Cardiovasc Interv 2016;9:1535-44.

27 Elias J, Hoebers LP, van Dongen IM, et al. Impact of chronic total occlusion location on LV function in ST-segment elevation myocardial infarction patients. J Am Coll Cardiol 2017:69:2347-8

28 Mashayekhi K, Neuser H, Kraus A, et al. Successful percutaneous coronary intervention improves cardiopulmonary exercise capacity in patients with chronic total occlusions. J Am Coll Cardiol 2017:69:1095-6.

29 Windecker S, Kolh P, Alfonso F, et al. 2014 ESC/EACTS Guidelines on myocardial revascularization: The Task Force on Myocardial Revascularization of the European Society of Cardiology (ESC) and the European Association for Cardio-Thoracic Surgery (EACTS)Developed with the special contribution of the European Association of Percutaneous Cardiovascular Interventions (EAPCI). Eur Heart J 2014;35:2541-619.

30 Elias J, van Dongen IM, Hoebers LP, et al. Improved recovery of regional left ventricular function after $\mathrm{PCl}$ of chronic total occlusion in STEMI patients: a cardiovascular magnetic resonance study of the randomized controlled EXPLORE trial. I Cardiovasc Magn Reson 2017;19:53. 